\title{
RESULTS OF SEARCHING FOR INNOVATIVE SOLUTIONS TO INCREASE THE FORMABILITY OF THIN SHEETS IN THE DEEP DRAWING PROCESS OF VEHICLE COMPONENTS
}

\author{
Monika HYRCZA-MICHALSKA \\ Silesian University of Technology, Faculty of Materials Engineering and Metallurgy, Gliwice, Poland, EU, \\ monika.hyrcza-michalska@polsl.pl
}

https://doi.org/10.37904/metal.2019.808

\begin{abstract}
The cold pressing of thin sheets is one of the dominant methods of manufacturing vehicle construction elements. These methods are constantly improving due to the production needs in an increasingly efficient way - economically and technologically effective. In addition, the modern user expects vehicles with ecofriendly features: low-emission, light, safe in operation, durable, corrosion-resistant, recyclable, etc. Car manufacturers are constantly looking for ways to meet these expectations. These expectations define the directions of following research on modern construction materials, e.g. advanced high strength steels (AHSS), multilayer and functional materials And the result of introducing production materials with new special properties, it creates numerous innovation needs in the field of their processing technology. In order to obtain very complicated and asymmetrical shapes of products, the liquid is used instead of rigid stamping tools (hydro-forming), metal materials are plasticized using partial heating (e.g. spinning with heating the area before the roll using a laser) or complete heating of the batch sheet (hot forming). The plates are deformed circumferentially on the instruments with a point tool whose movement path maps the shape of the single point incremental forming. Innovative hybrid solutions combining volumetric and shell forming, liquid treatment and hot forming, and the like are sought after. In this detailed work, the last of these hybrid technologies was analyzed, called quick plastic forming (QPF) with preforming. This technology is based on a new pre-forming process of deep drawing, on an innovative pressing tool with a unique system to regulate the time and pressure of the working liquid inside. The assumptions of technology have been presented. Requirements for the production of drawpieces from standard 5000 series aluminum alloys for the needs of the automotive industry, in relation to the capabilities of the analyzed technology, were compared.
\end{abstract}

Keywords: Deep drawing, formability of thin sheets, vehicle components, hydro-forming, hot forming

\section{INTRODUCTION}

Actually vehicle components design engineers have many possibilities of manufacturing methods selection for designed element made of thin sheet metal. They can select one standard forming method or combine them. If a charge material is very high strength or a shape of stamped element is complex they are also forced to look for more complex forming methods. Complex methods are hybrid very often. Then manufacturing method is combination of two processes or more and they use various additional process parameters, e.g. temperature (hot forming), working fluid in place of the rigid tool (hydromechanical forming, hydro-forming), friction and bulk forming (incremental forming) to increase the possibility of deformation of the charge material. Using the increase of the process temperature and hybrid methods is expensive, but the profit in the form very strong, construction-resistant elements compensates for the expenditures incurred. Review of deep drawing methods and an exemplary combination of standard and modern methods of sheet metal forming is included in Table 1. The representative of the automotive industry press shop undertook to implement innovation in manufacturing in the form of the use of hybrid sheet metal forming technology for vehicle components. With reference to publication [1,2], selected technology was assumed to be called quick plastic forming (QPF) with performing (QPFP). The paper presents an introduction to the undertaken research and implementation activities. 
Table 1 Comparison of exemplary standard and modern forming methods of vehicle components

\begin{tabular}{|c|c|}
\hline \multicolumn{2}{|c|}{ Forming methods of sheet metals } \\
\hline $\begin{array}{c}\text { Standard manufacturing methods of metal } \\
\text { forming in use: } \\
\text { Bending, stretching }\end{array}$ & $\begin{array}{c}\text { Modern and innovative (including hybrid) manufacturing } \\
\text { methods: }\end{array}$ \\
\hline Spinning & Bending using working liquid as a mandrel \\
\hline Roll forming & Spinning with initial heating with a laser spot = laser spinning \\
\hline $\begin{array}{c}\text { Cold forming (deep drawing) and forming at } \\
\text { elevated temperatures }\end{array}$ & Hydro-forming using use of batchcharges with closed cross-section, \\
e.g. tubes
\end{tabular}

\section{INNOVATIVE AND HYBRID TECHNOLOGIES - QUICK PLASTIC FORMING WITH PREFORMING (QPFP)}

The idea of quick plastic forming with preforming (QPFP) is based on super plastic forming [1] and is shown in Figure 1. Additionally heating of charge material on tool set is required and injection of working liquid neutral gas e.g. argon is necessary.

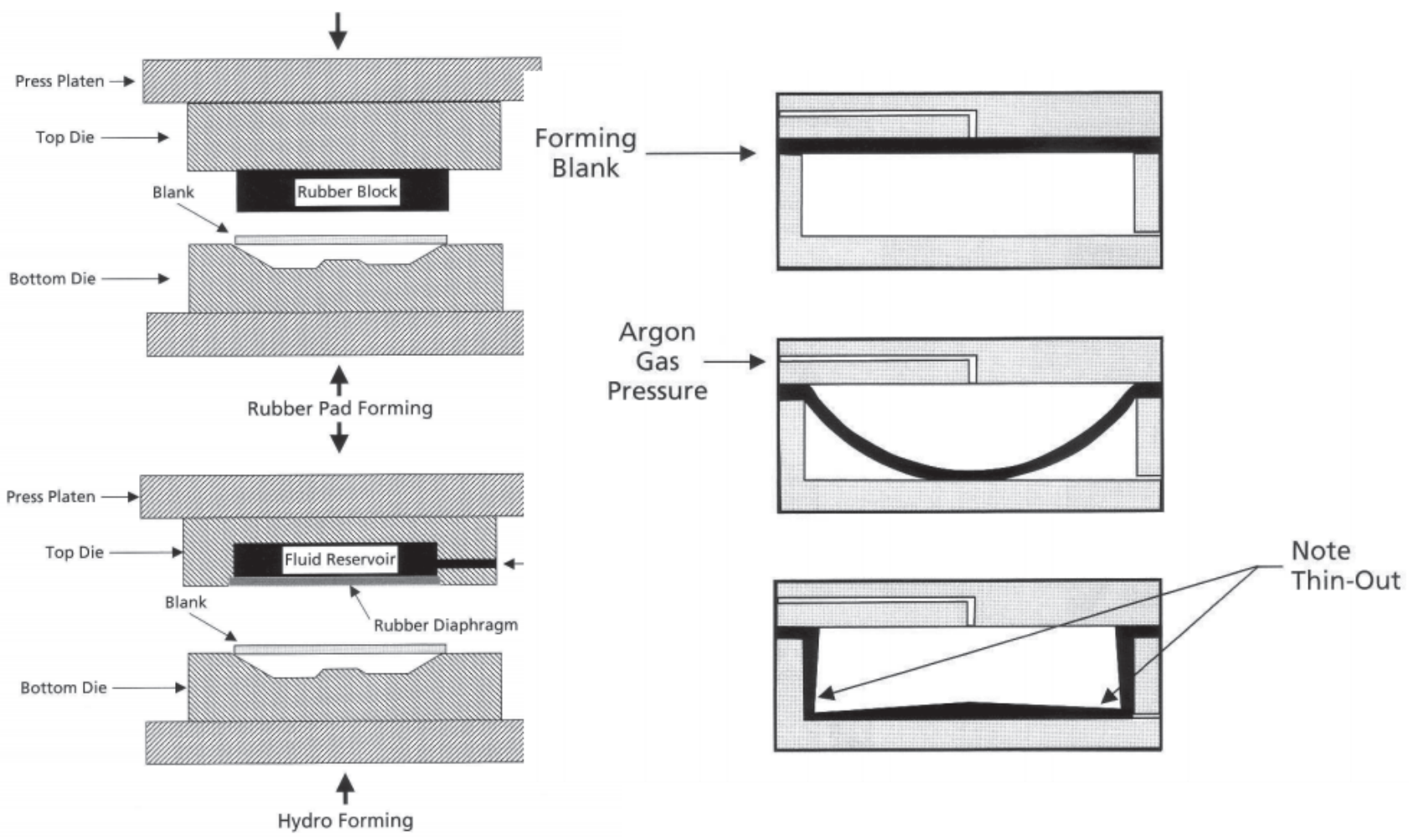

Figure 1 The idea of quick plastic forming according to $[1,3]$ 
Figure $\mathbf{2 a}$ shows special tool set for hot blow forming according to [2]. Figure $\mathbf{2 b}$ represents deep drawing drawipiece manufactured using QPFP method. Quick plastic forming with preforming method is also called hot blow forming according to quick gas injection. This method allows effective deep drawing of drawpiece from charge material which is not enough drawable in cold forming circumstances. This solution is dedicated to aluminum alloys and high strength steels.

(a)

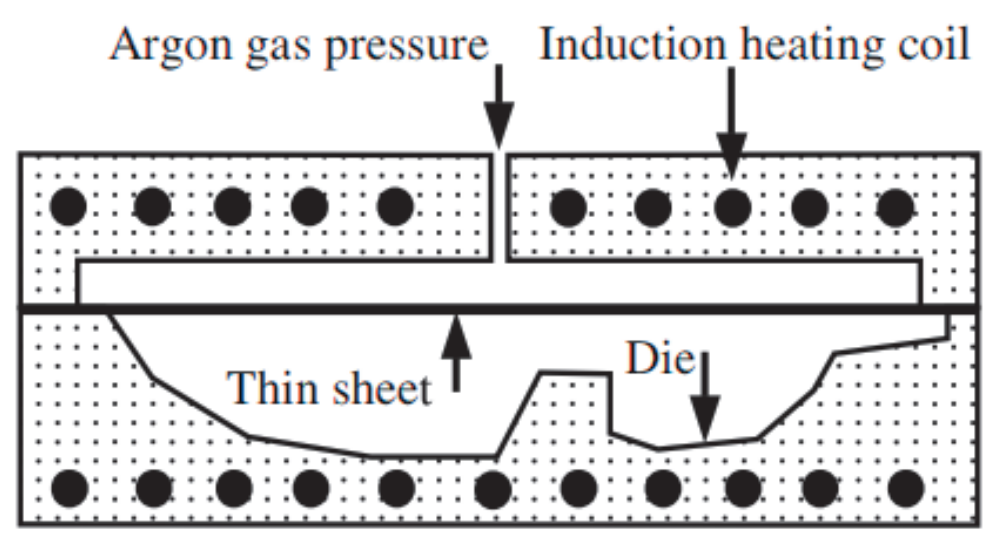

(b)

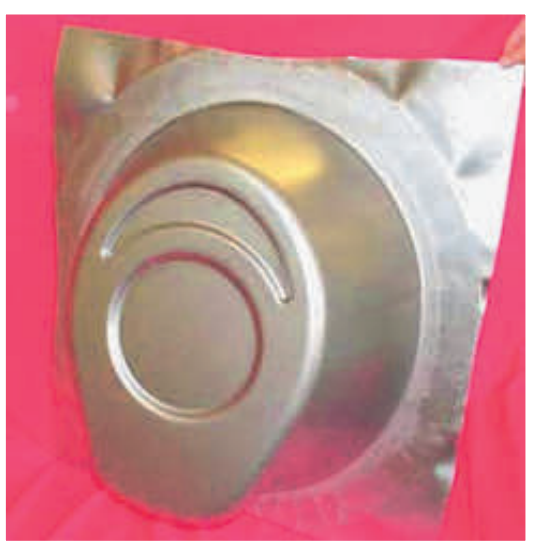

Figure 2 Hot blow forming: (a) tool set construction; (b) photography of real drawpiece formed using this manufacturing method [2]

\section{INDUSTRIAL SOLUTIONS}

Based on many experimental works [4-6] and own experiences method of manufacturing of complex shape car drawpiece, describe in chapter 2, had been analyzed and tested industrial. In press shop of IPB Polska Ltd. in Oświęcim Poland QPFP tools were designed and installed on hydraulic press machine. As a model drawpiece was selected car door drawpiece. The real structure of drawpiece is shown in Figure 3, while processed one is shown in Figure 4. For manufacturing drawpiece shown in Figure $\mathbf{3}$ was selected aluminum alloy 5000 series. Material properties of this alloy are given in Table 2 and chemical composition in Table 3.

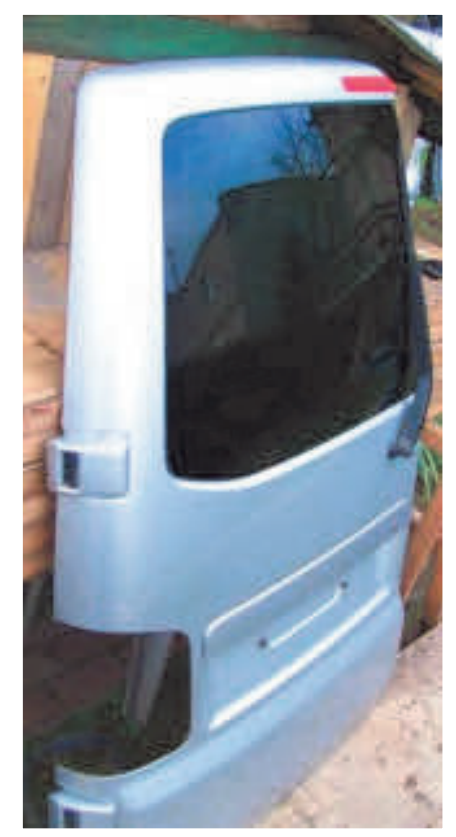

Figure 3 Drawpiece made by QPFP method - real car drawpiece 
Table 2 Material for QPFP mechanical properties

\begin{tabular}{|c|c|c|c|c|c|c|}
\hline Alloy & $\begin{array}{c}\text { Thickness } \\
{[\mathrm{mm}]}\end{array}$ & State & $\begin{array}{c}\text { TS } \\
{[\mathrm{MPa}]}\end{array}$ & $\begin{array}{c}\text { YS } \\
{[\mathrm{MPa}]}\end{array}$ & $\begin{array}{c}\text { A80 } \\
{[\%]}\end{array}$ & $\begin{array}{c}\text { E } \\
{[\mathrm{GPa}]}\end{array}$ \\
\hline 5083 SPF & 1.8 & $\mathrm{H} 18$ & 397.8 & 317.1 & 7.68 & 70.0 \\
\hline
\end{tabular}

Table 3 Material for QPFP chemical composition in wt. [\%]

\begin{tabular}{|c|c|c|c|c|c|c|c|c|c|}
\hline Alloy & Al & Si & Fe & Cu & Mn & Mg & Zn & Ti & Cr \\
\hline 5083SPF & rest & 0.4 & 0.4 & 0.1 & $0.4-1.0$ & $4.0-4.9$ & 0.25 & 0.15 & $0.05-0.25$ \\
\hline
\end{tabular}

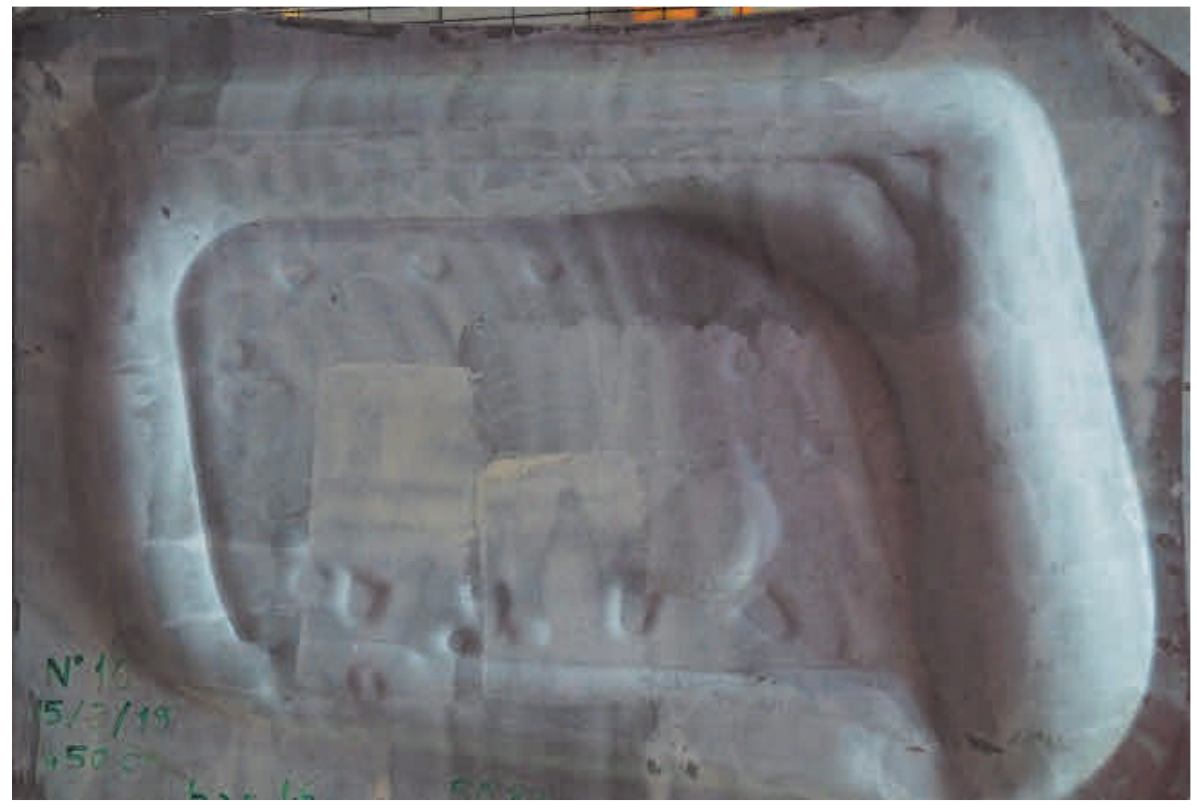

Figure 4 Drawpiece made by QPFP method - model drawpiece manufactured during industrial test at IPB Polska Ltd.

After many industrial trials of QPFP technology and selected 5083SPF aluminum alloy thin sheet proper times of preforming and forming of model drawpiece, were pointed out. Temperature of forming was established on level of $450{ }^{\circ} \mathrm{C}$ for tested alloy. Working neutral gas pressure and injection time to the tools were defined. Possibilities of QPFP forming method application were verified practically.

\section{CONCLUSION}

Based on superplastic forming, quick plastic forming with preforming technology was chosen for an industrial application in production of car drawpieces from 5000 series aluminum alloys. This forming method allowed realized highest value of elongation during bi-axial stretching with thickness reduction of initial blank than cold deep drawing of the same tested aluminum alloy or hot forming without using gas to preforming. Due to the increased shaping possibilities, this hybrid technology became also the source for the implementation of the innovative project by IPB Polska Sp.z o.o. in Oświęcim, Poland.

\section{ACKNOWLEDGEMENTS}

This work was supported by Polish Ministry for Science and Higher Education under internal grant BK-205/RM0/2019 for Institute of Materials Science, Faculty of Materials Engineering and Metallurgy, Silesian University of Technology, Poland. 


\section{REFERENCES}

[1] LACKI Piotr., ADAMUS Janina., MOTYKA Maciej. FEM simulation of superplastic forming of a spherical cap made of Ti-6Al-4V, Inżynieria Materiałowa, Vol. 31, no. 3, 2010, p.720-723.

[2] BONET Javier, GIL Antonio, WOOD Richard D., SAID Rajab, CURTIS Richard V. Simulating superplastic forming. Computer methods in applied mechanics and engineering 195 (48-49), p. 6580-6603.

[3] Project POIG.01.01.02-00-015/08-00 „Nowoczesne technologie materiałowe stosowane w przemyśle lotniczym” 2008-2015

[4] HYRCZA-MICHALSKA Monika. Research on liquid forming process of nickel superalloys thin sheet metals. Arch. Metall. Mater. vol. 62 iss. 4, 2017, p. 2355-2358.

[5] HYRCZA-MICHALSKA Monika, KAWALLA Rudolf, DEMBIŃSKA Joanna. Drawability studies of magnesium alloy sheets at elevated temperature. Arch. Metall. Mater. vol. 60 iss. 4, 2015, p. 2751-2756.

[6] HYRCZA-MICHALSKA Monika, GROSMAN Franciszek. The evaluate of laser welded tailor and tubular blanks formability for automotive vehicle elements stamping. Arch. Civ. Mech. Eng. vol. 9 nr 1, 2009, s. 69-81 